\title{
Shifting Ethnographic Paradigms and Practices: Unleashing From Colonialism
}

\author{
Indra Mani Rai (Yamphu)* \\ Kathmandu University, School of Education \\ Lalitpur, Nepal
}

\begin{abstract}
This paper demonstrates realist ethnographic paradigms and practices of engaging an extended period of time to collect the information of distinctive socio-cultural structures or institutions of alien tribal or indigenous societies and describing their cultural ways of life patterns in positivistic manner detaching them from the research process. It argues that the interpretive or hermeneutic wave of ethnography deconstructs this Western hegemonic research tradition giving birth to the interpretation of socio-cultural world of the researched attaching meaning to what they say and do. It further argues that the emergence of critical reflexive ethnographic tradition is the dramatic shift that challenges the colonial ethnographic practices giving space to the self as reflexive research participant. It helps to contest the colonial assumptions of structured and objective visualization of the world and authoritative representation of the other. The ethnographic tradition is further shifting towards promoting epistemic pluralism under postmodern ideologies employing multiple logics and genres to represent the self and the other. Auto/ ethnography that embodies the postmodern notions facilitates the researchers to release from the cage of colonialism serving to adopt multiple ways of knowing indigenously being self-reflexive participants in the research process.
\end{abstract}

Keywords: Reflexive, postmodern, auto/ethnography, colonialism, logics and genre

Ethnography is a specific form of qualitative inquiry. It enables us to research the realities embedded in a socio-cultural setting. It helps to understand the cultural world of the researched from their perspectives. Further, it intends to capture detailed and in-depth description of everyday life practices of people (Hoey, 2014). In so doing, it attempts to generate the realities from within how people in a particular socio-cultural setting behave, say, act or react, interact with each other, and perform their daily activities. Generally, it is understood that ethnography is a research process or method and product with cultural interpretation of the researched and the researchers' interpretation. However, the 
ethnographic research thoughts and traditions have been shifting from their original forms.

The ethnographic research traditions originated from anthropology in the nineteenth century (Wall, 2014). There is a common notion that the ethnography is equated with anthropology as its history goes back to studying culture of a particular group of people. This approach of qualitative research methodology has been widely used and adapted by the researchers from multiple disciplines such as sociology, education, and health and so on. With the use of ethnography in wider areas, its traditions have been shifting with the influence of philosophical ideas emerged at different points of time (Hammersley \& Atkinson, 2007).

This paper demonstrates the multiple shifts of ethnographic paradigms and practices. Moreover, it delineatesthe key philosophical turns (realist, interpretive/hermeneutic, critical, and postmodern) of ethnographyinfluencing the methodological traditions from conventional to postmodern forms. It attempts to highlight the emergence of ethnography and the subsequent sections deal with key philosophical and methodological shifts from colonial traditions to more self-reflexive traditions. Finally, the paper concludeswith my final insights on coherent discussion of multiple turns of ethnographic paradigms and practices. It argues that the reflexive critical and postmodern forms of ethnography facilitate the researcher to resist the traditional colonial forms of ethnographic traditions giving space to personal (researcher) articulation recognizing self as a vulnerable research participant.

\section{Realist Ethnography: Colonial Traditions}

The history of qualitative research traditions goes back to the early historical writing practices of cross-cultural accounts of people from different societies in ancient time of Herodotus (Erickson, 2011). This practice was followed by descriptive writing practices of everyday life which was flourished at the time of renaissance to the seventeenth century. The travelers used to generate the description of tribal or indigenous other. They developed a volume of pocketbooks comprising a number of questions and observation checklists to capture the multiple aspects of comprehensive and accurate account of the people of alien societies (Erickson, 2011). These forms of research traditions were adopted by the colonial administrators and travelers. The ethnographic traditionswere of survey types and were more structured and positivistic in nature.

Ethnography, a systematic and different form of research practice, emerged when Bronislaw Malinowski was trapped in Trobriand Islands, Papua New Guinea for many years during the World War I (Dourish, 2014). Hespent a longer period of time with the people having distinct cultural pattern. He shared the life patterns of the distinct group of people in terms of language, behavior, social practices and processes, and ways of living. Malinowskian ethnographic archetype was a pertinent oneto establish it as a distinct form of inquiry in native's cultural setting. Thiswas a form of research in which researcher engagedparticipating in the lives of people for a prolonged period of time and observing 
what they did, and how they acted, behaved, interacted, and practiced their culture.

Malinowski was a functionalist and was in favor of understanding and explaining the society from functionalist and positivistic perspectives. He viewed society as a human body. The society has been formed as a complex system of interdependent parts. He believed thatthe functioning of these parts can help the whole society to function. The research traditions were actually guided by this functionalist notion. Malinowskian scientific field work aimed "to describe customs and traditions, the institutions, the structure, the skeleton of the tribe (or what people say they do), to describe how daily life is actually carried out, and to record typical ways of thinking and feeling associated with the institutions and culture" (O'Reilly, 2005, p. 8.). Malinowski believed that survey can tell us about the framework of the society. He focused on "using concrete statistical documentation to record the organization of the tribe and anatomy of the culture, using minute and detailed observation to log the actual details of daily life and collecting ethnographic statements, narratives, utterances as documents of native mentality" (O'Reilly, 2005, p. 15).

This form of research tradition focused on describing socio-cultural patterns of behaviors and activities of the people to make fuller understanding of their cultural lives and documentation of their distinctive way of life patterns, beliefs, norms, and values. Thus, this classical ethnographic method included those that were traditionally used by anthropologists. They adopted multiple sources of data generation techniques such as fieldwork, observing activities of interest, recording field notes and observations, participating in activities during observations (participant observation), and carrying out various forms of informal and semi-structured ethnographic interviewing(Whitehead, 2005).

Malinowski (1922) advocates "grasping the native's point of view, his relation to life, and his vision of his world" (Erickson, 2011, p. 25). The representations of views of the researched in the writing of those whose daily actions are studied became a hallmark of ethnographic traditions in Malinowskian period. But, the Malinowskian ethnographic traditions were more descriptive and positivistic accounts of the culture of the researched. The presentation of social phenomena in a descriptive and straightforward way was used to tell real stories of the field. This was the realistic ethnographic tradition in which "the text is often presented in an explanatory foreword, along with the personal motivation behind his or her work" (Grenersen, 2005, p. 136). This classic realistic ethnography places its main focus on the subjectsin their own distinctive cultural circle. The ethnography was the account of what subjects say, do, and perhaps think, which were visible in the text. The descriptions of social structures or institutions or beliefs and values or culture of the researched were independent of the researcher. The researchers' personal background, interest and biases and personal experiences did not impact on the research process.

There were no rooms for alternative views or perspectives in the realist ethnography. The realist ethnographers viewed the structured social entities and organized social 
behaviors or patterned social activities of actors. They were rigid about presenting the real explanation of such ruled and patterned actions of people. "It was the scientific rationality of the Western world that was in a position to describe and it was the colonies that were described" (Grenersen, 2005, p. 177).Gradually, during the 1960s and 1970s, the realistic ethnographic tradition lost its absolute hegemony in ethnography. Ethnographers began to think and write their field experiences into the text breaking the conventional realist practices. The ethnographic researchers began to focus on generating experiences, meaning and interpretation influenced by semiotics and structuralism (Dourish, 2014).

\section{Interpretive/Hermeneutic Turn of Ethnography}

The hermeneutic turn (1970s) was another paradigmatic/practical shift of ethnography which placed the interpretive practices of culture at the core (Dourish, 2014). This wave was concerned about developing the conception of interpretation of the social world in multiple layers. The interpretation of the research participants of their social world and the researchers' interpretation of what has been interpreted by the researchedwas at the centreof this tradition. Thus, this wave surfaces the notion of being both the researcher and the researched as interpreters. The research participants make an understanding of their cultural world attaching meaning to the beliefs, practices, experiences, and culture and the researcher then makes accounts and interpretive explanations unpacking the meaning he/ she has constructed illuminating the world (Dourish, 2014).

This wave of ethnographic thoughts and traditions attempts to make an understanding interpreting the social and cultural phenomena from the researchers' point of view about what people do, what they understand, how they act in their cultural setting. This shift of ethnography focuses more on giving rise to multiple contextual meaning constructions of the researchers. This turn also emphasizes the issue of unstable or multiple forms of interpretations or non-existence of a single reality (Dourish, 2014). The anthropologists turn towards visualizing the cultural realities from the views of the researched. They start feeling the pains of research participants and focus on meaning making of the cultural world.

However, the ethnographers conducted their research without being self-critical. They did not think about their roles as researchers. They were less responsive to the self and did not think about the impact of the self to the research process. The ethnographers conducted their research without reflecting on the various conditions under which the research (O'reilly, 2005) was conducted. The ethnographic tradition was further strengthened by reflexive traditions of researchers in the ethnographic research process as an approach of decolonizing the research methodologies with the reference of critical theory (Smith, 1999). This was actually the political turn of ethnography. 


\section{Critical/Reflexive Turn of Ethnography}

The reflexive turn in ethnography, during 1980s, is a dramatic shift which enabled us to challenge or contest the colonial hegemonic, structured and scientific research practices (O'reilly, 2005). The ideas behind this reflexivity and reflexive practices came from critical theories. The reflexive thinking and traditions in ethnographic research appearfrom within the debate of presenting self or detachment of the self in the research process. It accentuates on putting the researchers' critical self-awareness at the core based on his/her experiences of the research process. The notion of reflexivity emerges from the issue of producing ethnographic texts reflecting the ethnographer's views or perspectives. The reflexivity of researchers appearsin textual production according to their "historical and socio-cultural backgrounds such as ethnicity, language, gender, religion, attitude, experience, political support, perceived interest, and allegiance" (Dourish, 2014, p. 15).

The reflexive turn of ethnography facilitated the researchers to visualize the world more critically. The ethnographic field work and texts were produced adding the critical dimension of questioning, doubting, and contesting the existing ideas. Beyond the depiction of ethnographic reflexivity in textual formation, the neo-Marxists anthropologists play the crucial role of changing the notion of ethnographic traditions towards reflexive practices seeing ethnographers themselves as vulnerable self or as research participants (Foley, 2002). The "ethnographers had often been members of a colonial power studying those colonized, or were middle class people studying working class, or men trying to understand women. In many cases, the relationship was an unequal one" (O'Reilly, 2005, p. 206). They studied the hierarchical economic status of people in the same society and the economic relationships of periphery countries (so called undeveloped countries) and core countries (developed countries) (Foley, 2002).The rise of this neo-Marxian attempt of visualizing political economies of core and periphery countriesdeveloped the critical thinking in ethnographic studies.

Further, the civil rights movement of around 1960s encouraged the activist anthropologists to study the oppressed groups. The ethnographic studies turned more political with a view to "struggle legally and partisan goals" for which the Neo-Marxists played a crucial role in shifting of ethnographic "study of classes as the social relation of production was transformed into the study of class cultures" (Foley, 2002, p. 15). They focused more on how the cultural identities are created and produced and reproduced perpetuating the inequalities in the society.

Moreover, the Post-Marxist critical ethnographers endeavored to generate knowledge needed to foster the democratic society and social justice. These critical ethnographers were influenced by Bourdieu's theoretical conceptions of "continuous inter-subjective knowledge construction and reconstruction, reflexive modes of social reality construction, and portrayal of cultural space and its people in dialogic manner" (Foley, 2002, p. 7). This 
theoretical notion was the foundations of contemporary critical ethnography of raising the voices of suppressed groups and depicting the injustice created by hierarchies and unequal power relationships.

Ethnographer like Hammersley (2006) seemed disinterested in raising the critical voices or the interests of these marginalized, exploited, and dominated groups through ethnographic research. This was because these orientations might create systematic bias.However, this critical ethnographic research has become a tool of emancipating and liberating such oppressed groups bringing their voices of injustice to the fore. This notion of critical research is another shift in recent years that helps to change the group for their betterment. The critical research becomes a "process of inquiry that goes beyond surface illusions to uncover the real structures in the material world in order to help people change conditions and build a better world for themselves" (Neuman, 2006, as cited in Henn, Weinstein, \& Foard, 2010, p. 32). It enables us to build knowledge to enhance the emancipatory consciousness making the research a powerful vehicle for challenging or contesting or questioning the existence of racial prejudice to give voice to the oppressed group. On the other hand, critical research approach helps to "add critical dimension of making critical analysis with critiquing ideology for the established policy and practice and establishes the role of researcher as an advocate or change agent who works towards a more equitable, fair and sustainable society" (Taylor \& Medina, 2011, p. 4).

The critical research tradition allows the researchers to demonstrate the critical selfawareness to understand complex societies. It helps us to reflect critically upon our own evolving subjectivities (false consciousness) throughout the process of inquiry (Taylor $\&$ Medina, 2011). Moreover, it also allows us to be responsive to self and reflexive on cultural, social, linguistic and ideological aspects of participants. It helps to acknowledge the orientations of shaping personal socio-historical locations, including the values and interests (Hammersley \& Atkinson, 2007). Because of the emergence of such significance of critical thinking, the ethnographic thinking and practices were more guided by these reflexive traditions.

Taking these ideals of critical theory as referent, the Western colonial research (positivistic traditions) assumptions and values are deconstructed (Smith, 1999). The colonizers' structured, objective and neutral visualization of the world and authoritative representation of the other (Smith, 1999) is challenged. The colonizers' hegemonic research practices recognized the stories of colonizers as universal truths and the stories of indigenous others are marginalized.The self-reflexive research allows us to make contestation of the Western colonial research practices and to adopt indigenous methodologies of cultural procedures, values and behaviors (Smith, 1999). It helps to challenge the dominance of traditional research traditions and employs indigenous and multiple ways of knowing (Wall, 2008) enabling us to be reflexive on our own social world and conducting the field work in culturally appropriate ways. This wave of ethnographic 
traditions helps us to foster post-modern thinking focusing more on unpacking personal lived experiences to represent the multifaceted and multi-hued nature of self-consciousness and awareness. The postmodern notion tries to see the relations of personal and cultural world reflexively.

\section{Postmodern Wave of Ethnography}

Postmodern ethnography is more guided by the thought that the colonial research traditions are felt more suppressive. They enter into culture exploiting the culture sharing groups and report for monetary or professional gain disregarding the relational ties with the cultural groups (Ellis, Adams, \& Bochner, 2011). These colonial practices of generating knowledge ignore the indigenous methodologies of adopting cultural procedures, values and behaviors. In this context, the indigenous ways of knowing enable us to think reflexively being a part of the research design and disseminating research results going back to the community in culture sensitive ways (Smith, 1999). Postmodern research ideas come out onto the surface from within this dilemma of imposition and resistance of colonial ideas of knowledge generation approaches.

The ideas of reflexivity and reflexive research practices are shared by the postmodern ethnography. Postmodern ethnography owns the reflexivity as a paramount epistemic orientation. The spread of sensibility of post-modern ideas in ethnographic traditions believes in non-existence of power dynamics in the socio-cultural setting or between the researchers and the researched (Tedeschi, 2013). The post-modern notion again facilitates to contest the Western colonial ideas of ethnographic research traditions. It evolves in resistance of political domination of the Western modes of realist ethnography giving rise to indigenous ways of knowing self reflexively. It focuses on presenting the lived experiences of the self in stories. It focuses on textual construction in respectful and culture sensitive ways. This is the way of giving space to represent the colonized ones. Thus, a post-modern ethnography is a democratic solution to knowing the world indigenously.

The emphasis of postmodernism is on multiple views or perspectives of participants and construction of multiple literary genres. There are three components of the postmodern ethnography: "attention towards the subjectivity of the researcher, dialogue with the social subjects, creativity in the manner of communicating research results" (Tedeschi, 2013, p. 10). The postmodern ethnography allows us to unpack our own vulnerability and places the "first-person narrating voice portraying as one of the characters participating subjectively in the research story as a person engaging in a relationship with the other" (Tedeschi, 2013, p. 11). The narrative approaches in postmodern ethnography are now changing to facilitate a more personal point of view by emphasizing reflexivity and personal voice and recognizing the researcher as representative of a multilayered life world (Duncan, 2004).

In addition, post-modern ethnography emphasizes the issues of epistemic pluralism and arts-based approach to representing the social realities. It emphasizes the arts-based 
approaches of creating space for "the sharing of unique, subjective, and evocative stories of experience that contribute to our understanding of the social world" (Wall, 2006, p. 5). It helps to promote epistemic plurality representing the social world through arts employing multiple logics and genres (metaphors, narratives, imageries, poems, drama, and so on) which enable us to understand the social world comprehensively (Taylor, Taylor, \& Luitel, 2012). It believes in unpacking the lived experiences of the self (Smith, 1999) through these multiple logics and genres.

The postmodern ethnography allows us to communicate the research results representing the researched with more authentic and incisive than the conventional ethnographic methods (Tedeschi, 2013). In so doing, it facilitates the researcher to include the researched creating their descriptions through artistic ways. The ethnographer creates the negotiated writings. The artistic nature of auto-ethnography enables us to explore our associations with the culture. In addition, it allows us to develop collaborative approaches of research with the researched articulating our lived experiences continuously in a dialogic manner in textual form for the illumination to the readers. It provides us to space for exploring, presenting and representing the self (Haynes, 2011).

The ethnographic research strength is to be judged more by the quality of the representation of lived reality than with how much time one spent in living this with the participants (Forsey, 2010). The representation of realities or our thoughts and feelings through various means of communication like language and arts or multiple logics and genres (Taylor \& Medina, 2011) is the postmodern methodological shift in ethnography. This is because "arts-based modes of expression provide unique opportunities for contemporary ethnographers to portray the process of coming to know in thoughtful, emotional, and spiritual terms, enabling them to express heartfelt moral concerns" (Taylor \& Wallace, 2007, p. 4).

Autoethnography, which was in existence prior to postmodern thoughts of inquiry, fits best with the aims and methods of postmodern ethnography as it relies more on selfreflexive nature of inquiry (Tedeshi, 2013). Itenables us to make "positive response to critiques of canonical ideas about what research is and how research should be done" (Ellis et al., 2011, p. 7). It helps us to concentrate on producing meaningful, accessible, and evocative research grounded in personal experience (Ellis \& Bochner, 2000). These are the ways that facilitate ethnographers to resist the colonial research traditions.

Autoethnography allows creating insider position in the research process (Tedeschi, 2013). Creating insider position is imperative to address the growing importance of reflexivity (Breen, 2007). Representation of social realities through reflexive practicesis a paramount epistemology in today's ethnographic studies. Insider ethnographic researchesfacilitate us to study our own culture sharing groups and professionals to study the professional practices. Holding insider position allows us to articulate emic views. There are three key strengths of insider research of "a superior understanding of the group's 
culture; the ability to interact naturally with the group and its members; and a previously established, and therefore greater, relational intimacy with the group" (Bonner \& Tolhurst, 2002, as cited in Breen, 2007, p. 5). This positioning offers significant potential benefits in terms of practical issues such as access and rapport (Hodkinson, 2005) and bond of trust with the researched. In addition, for an insider researcher, initial proximity helps to be reflexive in the research process. This positioning enables us to conduct the research reflecting self and situating self in the research process (Dwyer \& Buckle, 2009). The critical reflexive and postmodern approaches of researching self and other facilitate us to unleash ourselves from the colonial research practices.

\section{Wrapping Up}

Realist ethnographylegitimizes the positivistic research traditions of describing the socio-cultural structures or institutions of tribal or indigenous other visualizing the society from functionalists' point of views (society as a complex system of interrelated or interdependent parts). The realist anthropologists engage in the field fora prolonged period of time sharing the lives of participants, understanding and learning their distinctive cultural lives, and interacting and observing their social beliefs, norms, and values. The realist colonizers develop descriptive accounts of cultural other without their representation. This hegemonic research traditions are more suppressive to the indigenous other.

This methodological archetype is deconstructed by the interpretive or hermeneutic traditions of attaching meaning to the socio-cultural world of the researched.The ethnographic traditions move towards multiple interpretations of the researched and the researchers through meaning making. The hermeneutic nature of ethnographic traditions leads to the more political nature of ethnographies considering the importance of reflexivity of the researchers. The researchers' self-reflexivity with dialogic writing visualizing the thoughts under hierarchies and unequal power relationshipis one of the dramatic shifts of ethnographic traditions. This is a form of contesting colonizers' hegemonic realist ethnographic practices. The reflexive ethnographic research traditions create spaces for presenting the self as a vulnerable research participant. This research enables us to represent the cultural other in textual forms. It helps to contest the colonial assumptions of structured and objective visualization of the world and authoritative representation of the other.

The postmodern ethnography, guided by postmodern philosophy, shares the critical reflexive traditions that facilitate us to challenge the colonial research practices and classical Western ways of knowing. It promotesmultiple ways of knowing or epistemic pluralism. This provides the representation of the self and other. The critical auto/ethnography that embodies with the postmodern ideas unleashes the indigenous ethnographers from the classical colonial ethnographic traditions adopting culture sensitive epistemic plurality. The postmodern ethnography facilitates in the representation of cultural self and other through multiple logics and genres accepting the ethnographers as absolute 
research participants. Thus, critical reflexive and postmodern ethnographic ideas and practices are helpful in decolonizing the traditions of ethnography.

\section{References}

Breen, L. J. (2007). The researcher 'in the middle': Negotiating the insider/outsider dichotomy. The Australian Community Psychologist, 19(1), 163-174.

Dourish, P. (2014). Reading and interpreting ethnography. In J. S. Olson \& W. A. Kellogg (Eds.), Ways of knowing in HCI (pp. 1-23). New York, NY: Springer.

Duncan, M. (2004). Autoethnography: Critical appreciation of an emerging art. International Journal of Qualitative Methods, 3(4), 1-14.

Dwyer, S. C., \& Buckle, J. L. (2009). The space between: On being an insider-outsider in qualitative research. International Journal of Qualitative Methods, 8(1), 54-63.

Ellis, C., \& Bochner, A. P. (2000). Autoethnography, personal narrative, and personal reflexivity. In N. K. Denzin \& Y. S. Lincoln (Eds.), Handbook of qualitative research (2nd ed., pp. 733-768). Thousand Oaks, CA: Sage.

Ellis, C., Adams, T. E., \& Bochner, A. P. (2011). Autoethnography: An overview. Forum Qualitative Sozialforschung / Forum: Qualitative Social Research, 12(1), Art. 10. Retrieved from http://nbn-resolving.de/urn:nbn:de:0114-fqs1101108

Erickson, F. (2011). A history of qualitative inquiry in social and educational research. In N. K. Denzin \& Y. S. Lincoln (Eds.), The Sage handbook of qualitative research (pp. 97-128). Los Angeles, LA: Sage.

Foley, D. E. (2002). Critical ethnography: The reflexive turn. International Journal of Qualitative Studies in Education, 15(4), 469-490.

Forsey, M. G. (2010). Ethnography as participant listening. Ethnography 11(4), 558-572. doi:10.1177/1466138110372587

Grenersen, G. (2005). The ethnographic tradition in social science: Between the boundaries of the classic scientific ideal and personal experience. Retrieved from http://www. septentrio.uit.no/index.php/nordlit/article/download/1083/1034

Hammersley, M. (2006). Ethnography: Problems and prospects. Ethnography and Education, 1(1), 3-14.

Hammersley, M., \& Atkinson, P. (2007). Ethnography: Principles in practice (3rd ed.). New York, NY: Routledge.

Haynes, K. (2011). Tensions in (re)presenting the self in reflexive autoethnographical research. Qualitative Research in Organizations and Management: An International Journal, 6(2), $134-149$.

Henn, M., Weinstein, M., \& Foard, N. (2010). A critical introduction to social research (2nd ed.). New Delhi, India: Sage.

Hodkinson, P. (2005). Insider research in the study of youth cultures. Journal of Youth Studies, 8(2), 131-149. 
Hoey, B. A. (2014). A simple introduction to the practice of ethnography and guide to ethnographic field notes. Retrieved from http://works.bepress.com/brian_hoey/12 O'reilly, K. (2005). Ethnographic methods. London, England: Routledge.

Smith, L. T. (1999). Decolonizing methodologies: Research and indigenous peoples. London, England: Zed Books.

Taylor, P. C., \& Medina, M. (2011). Educational research paradigms: From positivism to pluralism. College Research Journal, 1(1), 1-16.

Taylor, P. C., \& Wallace, J. (2007). Contemporary qualitative research for science and mathematics educators. In P. C. Taylor \& J. Wallace (Eds.), Qualitative research in postmodern times: Exemplars for science and mathematics educators (pp. 1-12). Netherlands: Springer.

Taylor, P. C., Taylor, E. L., \& Luitel, B. C. (2012). Multi-paradigmatic transformative research as/for teacher education: An integral perspective.In B. J. Fraser, K. Tobin, \& C. J. McRobbie (Eds.), Springer international handbooks of education (pp. 373-387). New York, NY: Springer.

Tedeschi, E. (2013). Words for the other: Ethnographies of diversity. Italian Sociological Review, 3(1), 13-26.

Wall, S. (2006). An autoethnography on learning about autoethnography. International Journal of Qualitative Methods, 5(2), Art. 9. Retrieved from http://www.ualberta. $\mathrm{ca} / \sim$ iiqm/backissues $/ 5 \_2 / \mathrm{html} /$ wall.htm

Wall, S. (2008). Easier said than done: Writing an autoethnography. International Journal of Qualitative Methods, 7(1), 38-53.

Wall, S. (2014). Focused ethnography: A methodological adaption for social research in emerging contexts. Forum Qualitative Sozialforschung / Forum: Qualitative Social Research, 16(1), Art. 1. Retrieved from http://nbn-resolving.de/urn:nbn:de:0114fqs 150111

Whitehead, T. L. (2005). Basic classical ethnographic research methods: Secondary data analysis, fieldwork, observation/participant observation, and informal and semi-structured interviewing. Retrieved from http://www.cusag.umd.edu/documents/ workingpapers/classicalethnomethods.pdf 